\title{
WASPS FEEDING ON COMB-HONEY
}

\author{
By Phil Rau \\ Kirkwood, Missouri
}

When a plate of honey is placed out-of-doors to attract honeybees, it is interesting to see how quickly wasps are also attracted to it. Honey in a tin plate is certainly different in its setting and in its quality from the weak nectar in the flowers which wasps are accustomed to patronizing.

But if wasps and honey-bees are attracted to honey, it is strange indeed that solitary bees are not likewise attracted to it. In the clay bank in my garden, not far from the honey dish, many Anthophora abrupta, Osmia cordata, O. lignaria were nesting but none of these ever came to the honey. In the wooden frame above the clay bank many $X$ ylocopa virginica were also nesting and even though I have often fed them honey from a glass rod while they were trying to extract nectar from the flowers, I have never seen Xylocopa go to the honey-plate.

Many bumble-bees, Bombus americanorum, visit the flowers nearby, but none of them are attracted to the honey in the dish. Do wasps and honey-bees learn more quickly than wild bees that honey is a richer food than nectar, and that honey in a dish is more accessible than nectar in the flowers?

The following wasps have often been seen feeding from a dish of honey:

Monobia quadridens I., both sexes.

Eumenes fraternus Say.

Sceliphron camentarium Drury.

Polistes pallipes Lepel.

Polistes variatus Cress.

Vespula maculifrons Buyss., workers.

Arachnophroctonus ferrugineus Say.

Honey-bees, as already stated, were easily attracted to a dish of honey in the grass, but what is surprising is that the dipterous, heavy-bodied mimic of the honey-bee, Eristalis tenax L. [C. T. Greene] was also often attracted to it and ate heavily of the honey. 

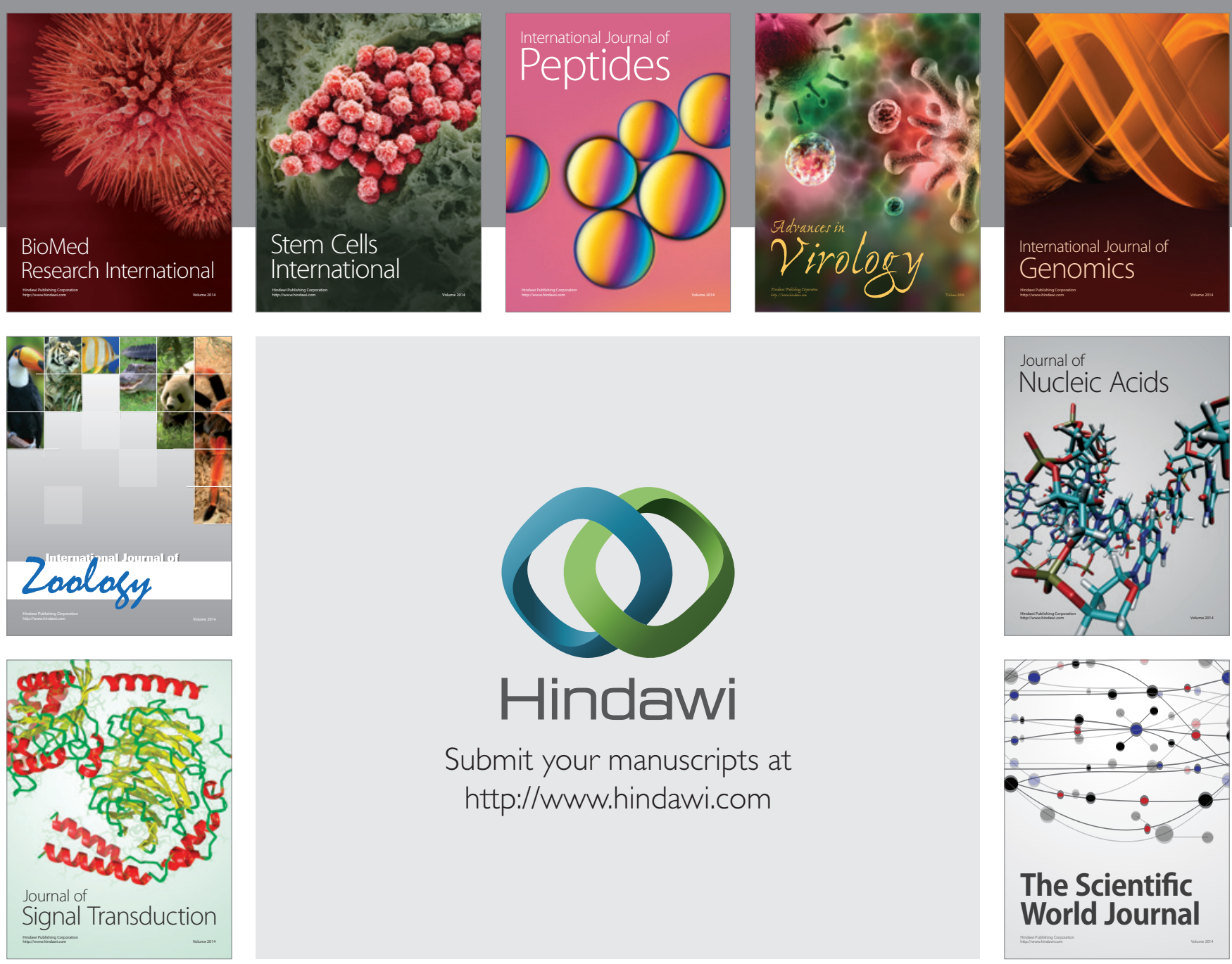

Submit your manuscripts at

http://www.hindawi.com
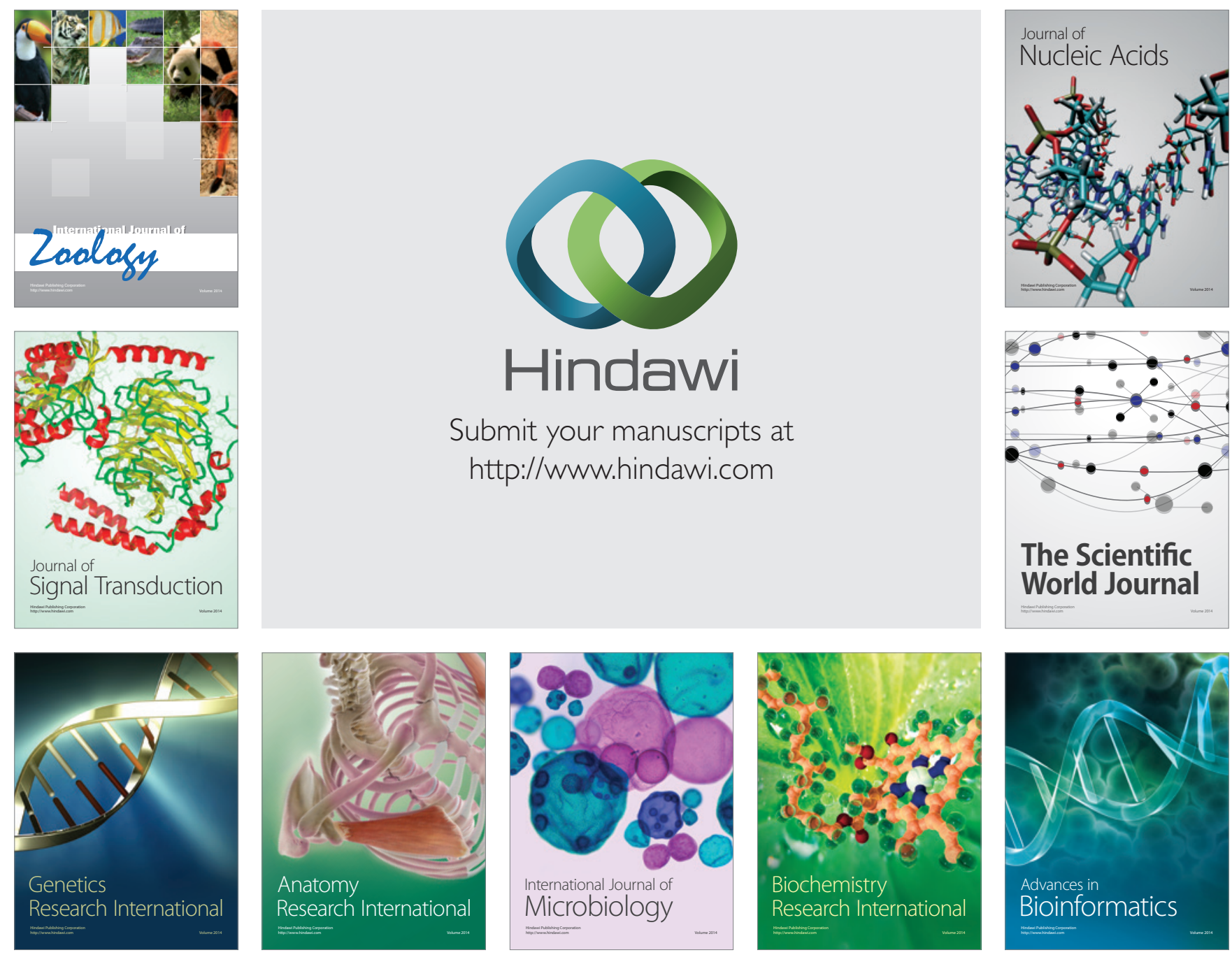

The Scientific World Journal
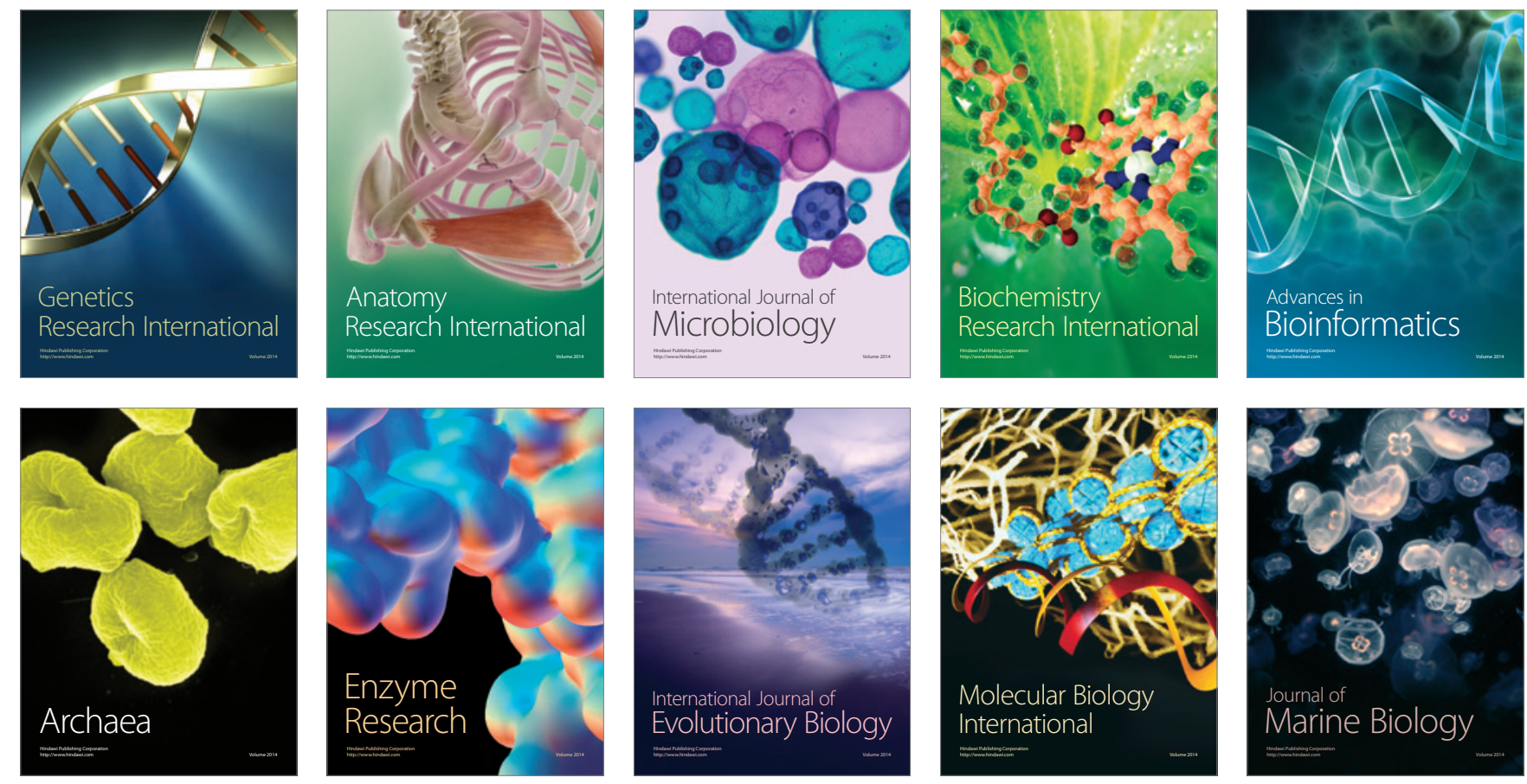